\title{
PROPUESTA PARA UNA SECUENCIA HISTÓRICA DEL ZIGURAT DE BABILONIA
}

\author{
Juan Luis Montero Fenollós \\ (Universidade da Coruña)
}

\begin{abstract}
RESUMEN
La vida y la evolución de la ciudad de Babilonia estuvieron ligadas a la de su principal monumento religioso, el zigurat llamado Etemenanki. A partir de las fuentes escritas y de la documentación arqueológica se hace una propuesta provisional sobre las distintas fases históricas (construcción, destrucción y reconstrucción) de la célebre torre escalonada (desde sus origenes, probablemente en Ur III, hasta la época helenística).
\end{abstract}

\section{PALABRAS CLAVE}

Zigurat, Babilonia, cronología.

\section{THE HISTORICAL SEQUENCE OF THE ZIGGURAT OF BABYLON: A PROPOSAL}

\section{RÉSUMÉ}

La vie et l'évolution de la ville de Babylone étaient liées à celle de son principal monument religieux, la ziggurat nommée Etemenanki. À partir des sources écrites et de la documentation archéologique, une proposition provisoire est faite sur les différentes phases historiques (construction, destruction et reconstruction) de la célèbre tour à étages (depuis ses origines, probablement à Ur III, jusqu'à la période hellénistique).

\section{MOTS CLÉ}

Zigurat, Babylone, chronologie.

La historia del Etemenanki, el zigurat de Babilonia, es ciertamente compleja y difícil de organizar por la falta de documentación textual y de evidencias arqueológicas. Los trabajos de excavación llevados a cabo en 1962 en los restos del núcleo del monumento permitieron a Hansjörg Schmid establecer una secuencia de tres fases constructivas. La más antigua estaría constituida por un núcleo de adobe, que formaba una planta cuadrangular de $65 \mathrm{~m}$ de lado; la segunda consistía en un revestimiento de adobe que daba lugar a un edificio con una base de $73 \mathrm{~m}$ de lado y, finalmente, la tercera fase estaba definida por otro revestimiento, en este caso de adobe cocido, que delimitaba un monumento con una base de $91 \mathrm{~m}$ de lado. El arquitecto alemán ha explicado este esquema constructivo de la siguiente manera: la primera torre de pisos sería aquella que fue destruida por el rey Senaquerib y construida inicialmente en época Paleobabilónica; la segunda sería el resultado de la reconstrucción de los reyes asirios Asarhadón y Asurbanipal; y la tercera sería obra de Nabopolasar y Nabucodonosor II $^{1}$.

Andrew George ha propuesto otra interpretación sobre la secuencia cronológica del zigurat de Babilonia. El asiriólogo británico considera que el zigurat de $91 \mathrm{~m}$ de base debía ser más antiguo y plantea una posible datación entre los siglos XIV y IX a.C. Los otros dos zigurats más arcaicos (de 65 y 73 m de base) se remontarían a mediados del II milenio a.C., sin descartar la época Paleobabilónica ${ }^{2}$. Los textos de este período no hablan sobre la construcción de la torre de pisos de Babilonia. Pero este silencio no es argumento suficiente para descartar la existencia

\footnotetext{
${ }^{1}$ Schmid 1995, pp. 69-74.

${ }^{2}$ George 2005/2006, pp. 87-88.
} 
de un zigurat a comienzos del II milenio a.C. Además, es posible que el código de leyes de Hammurabi contenga la que podría ser la primera alusión escrita al zigurat de Babilonia: "ils eurent établi pour lui (Marduk), au milieu d'elle (Babylone), une éternelle royauté dont les fondements sont aussi définitivement assurés que ceux des cieux et de la terre..."3. Esta expresión recuerda mucho el significado del nombre ceremonial en sumerio del zigurat de Babilonia, el Etemenanki ("Casa que es el fundamento del cielo y de la tierra").

Parece coherente pensar que la historia del zigurat es el reflejo directo de la secuencia cronológica de la ciudad que lo acogía y que lo vio nacer. La primera mención escrita indiscutible sobre Babilonia se data en tiempos del rey acadio Shar-kalli-sharri, en la que se hace referencia al año en que este rey acadio construyó los fundamentos de los templos de Annunitum y de Ilaba ${ }^{4}$.

La percepción de los reyes neobabilónicos de que Babilonia era una ciudad antigua, que había sido sede del poder de la dinastía acadia, parece responder a una realidad histórica ${ }^{5}$. Nabopolasar y sus sucesores justificaron el prestigio de su política basándose de la gran antigüedad de Babilonia y en la implicación de la dinastía acadia en su fundación y desarrollo. A sus ojos, Babilonia era la "Nueva Akkad"'. El propio rey Nabopolasar alude, en una inscripción sobre la reconstrucción de la muralla (Imgur-Enlil) de Babilonia, a la antigüedad de la ciudad con motivo del hallazgo en el curso de los trabajos realizados de la escultura real de uno de sus predecesores. Esta ha sido interpretada como una estatua inscrita perteneciente a un rey de la dinastía de $\mathrm{Akkad}^{7}$. Babilonia también aparece citada en textos administrativos de la III dinastía de Ur; en ellos se hace referencia a la existencia de un gobernador y al pago de tasas a una entidad central ${ }^{8}$.

Los orígenes de Babilonia pueden ser más antiguos aún, a la luz de otras evidencias epigráficas datadas a mediados del III milenio a.C. Procedente de Babilonia se conserva parte de una inscripción votiva en piedra caliza donde aparece escrito BAR.KI.BAR, un topónimo que podría ser Babbar o Baba(r/l), es decir, Babilonia9. De igual manera, sabemos que fragmentos de cerámica del período Dinástico Antiguo III han sido recogidos en la superficie de dos sectores del yacimiento, en Tell Amran y al oeste de Homera ${ }^{10}$.

La historia de Babilonia y la de su célebre torre escalonada son inseparables. Esto hace pensar que el primer zigurat de Babilonia se remontaría al origen de la ciudad, a datar con probabilidad a finales del III milenio a.C. Un análisis de la geometría del plano de la ciudad pone de manifiesto que el Etemenanki ocupaba un lugar central en el conjunto de la organización urbana. Situar el zigurat en el centro del sistema fue un acto voluntario de fundación, que concebía el zigurat como un elemento central y coordinador ${ }^{11}$. Parece lógico pensar que la fundación de Babilonia pudo tener lugar cuando el zigurat se impuso como monumento clave de la vida religiosa en las principales ciudades mesopotámicas a partir de la III dinastía de Ur (ca. 2100 a.C.). Aunque, como acabamos de ver, Babilonia aparece citada en textos del III

\footnotetext{
${ }^{3}$ Finet 2004, p. 33. Prólogo I, 20. Véase también el epílogo R XXIV, 70 (p. 142).

${ }^{4}$ Frayne 1993, p. 183 (iii, k).

${ }^{5}$ En una inscripción, Nabucodonosor II usó el término acadio abum (padre o antepasado) para referirse al soberano acadio Naram-Sin. En otra inscripción Nabónido describe a Sargón no como rey de Akkad, sino como rey de Babilonia. Véase Beaulieu 2003, p. 6.

${ }^{6}$ Beaulieu 2003, p. 6.

${ }^{7}$ Beaulieu 2003, p. 3-5.

${ }^{8}$ Lambert 2011, p. 71.

${ }^{9}$ Lambert 2011, p. 72-73; George 1992, p. 253.

${ }^{10}$ Gibson 1972, p. 149.

${ }^{11}$ Margueron 2001.
} 
milenio a.C. ${ }^{12}$., no hay, sin embargo, ninguna prueba sobre la existencia de esta torre primigenia en Babilonia. Se trata, por tanto, de una hipótesis.

La historia del zigurat de Babilonia a lo largo del II milenio a.C. está sumida en la más absoluta oscuridad tanto a nivel textual como arqueológico. No obstante, hay una serie de listas de templos y de textos litúrgicos, copias del I milenio a.C. de originales más antiguos de difícil datación, que contienen referencias al Etemenanki. Entre ellos se encuentran los textos topográficos Tintir, compuestos tal vez en el reinado de Nabucodonosor I (1126-1105 a.C.); el Poema de la creación, a datar probablemente en un período similar y donde se habla de la construcción del Esagil y de "la haute tour à étages de ce nouvel Apsû" (con toda probabilidad el Etemenanki) ${ }^{13}$; y la lista de zigurats de Kujunjik, cuya fecha de composición probable es el período Kasita ${ }^{14}$.

Es cierto que, entre el período Paleobabilónico y la dominación Neoasiria, el rey Nabucodonosor I fue el más carismático de los monarcas con capacidad política y económica para planificar y construir o reconstruir un monumento de la envergadura del zigurat de Babilonia ${ }^{15}$. Pero no fue el único. Otros soberanos que desarrollaron una importante actividad edilicia en Babilonia fueron Kurigalzu I (ca . 1400 a.C.), Marduk-shâpik-zêri (1082-1070 a.C.) y Adad-apla-iddina (1069-1048 a.C.). Es probable que pudieran haber dejado alguna huella en el zigurat de Babilonia. En el Poema de Erra se menciona al Etemenanki por su nombre ${ }^{16}$. Este poema es una composición de datación incierta, posiblemente entre los siglos XI-IX a.C. ${ }^{17}$.

La primera mención del zigurat de Babilonia en un texto propiamente histórico procede de una inscripción del rey asirio Senaquerib, que destruyó la ciudad en 689 a.C. ${ }^{18}$. En respuesta a las rebeliones que terminaron con el asesinato de Asur-nâdin-shumi, hijo de Senaquerib que él había puesto en el trono de Babilonia, los ejércitos de Asiria saquearon la ciudad. La venganza fue terrible, pues Senaquerib destruyó sus templos y profanó sus estatuas sagradas. La estatua del dios Marduk fue trasladada a Nínive, la capital asiria: "Les murs d'enceinte intérieur et extérieur, temples et dieux, la ziggurat de briques et de terre, autant qu'il y en avait, je rasai et je les jetais dans l'Euphrate." 19 .

Su hijo y heredero, el rey Asarhadón (680-669 a.C.), inició la reconstrucción de la ciudad Babilonia, cuyo verdadero alcance no es conocido. Durante su reinado invirtió grandes medios en la reparación de los principales monumentos, entre ellos el zigurat, que por primera vez en una inscripción real aparece citado como Etemenanki ${ }^{20}$. Se conservan también varias cartas en las que se informaba al rey asirio de los avances de las obras de restauración de los templos de la ciudad ${ }^{21}$. Asurbanipal continuó con las labores de restauración emprendidas por su padre en la ciudad. De ambos monarcas neoasirios se conservan varios adobes con una inscripción en la que se conmemoran los trabajos llevados a cabo en el Etemenanki ${ }^{22}$.

Pormandato de Marduk, el rey Nabucodonosor II culminó, hacia 590 a.C., la reconstrucción de las obras iniciadas por su padre Nabopolasar en el zigurat de Babilonia. Sobre estos trabajos, que finalizaron con la construcción del templo de la cima, se conservan varias inscripciones

\footnotetext{
${ }^{12}$ Lambert 2011, p. 71.

${ }^{13}$ George 1992, p. XXX, tablilla IV; Bottéro y Kramer 1993, p. 641 (VI, 63).

${ }^{14}$ George 1993, p. 45-46.

${ }^{15}$ Von Soden 1971, p. 258-259.

${ }^{16}$ Bottéro y Kramer 1993, p. 687 (I, 128).

${ }^{17}$ George 1992, p. 299; George 2005/2006, p. 79.

${ }^{18}$ George 1992, p. 299.

${ }^{19}$ André-Salvini 2001, p. 34.

${ }^{20}$ George 1992, p. 299.

${ }^{21}$ Cole y Machinist 1998, textos no $161-170$ y 173-180.

${ }^{22}$ Frame 1995, B.6.31.4-9, B.6.32.8, 10 y 11.
} 
cuneiformes y la llamada estela de la torre de Babel ${ }^{23}$. De Nabónido, hay un fragmento de tablilla en el que se hace referencia a trabajos en el muro del recinto del Etemenanki ${ }^{24}$.

Las excavaciones de Hansjörg Schmid han documentado evidencias arqueológicas de una destrucción deliberada del zigurat de Babilonia, en particular de las escaleras de acceso y del manto de revestimiento ${ }^{25}$. Sabemos que ca. 484 a.C. el rey persa aqueménida Jerjes I puso fin a una rebelión en Babilonia con la demolición parcial del zigurat y la interrupción del culto al dios Marduk. De esta destrucción se hacen eco diversos autores grecorromanos, como Estrabón y Arriano ${ }^{26}$. Parece lógico relacionar las evidencias arqueológicas sacadas a la luz por el arquitecto alemán con las informaciones de los textos clásicos y atribuir al rey Jerjes la destrucción del Etememanki, el templo alto de Marduk en Babilonia ${ }^{27}$. Sin embargo, algunos autores consideran que estas fuentes son demasiado tendenciosas y parciales para ser valoradas como una información históricamente válida ${ }^{28}$. Los historiadores griegos gustaban de presentar a Jerjes como un soberano intolerante y cruel, contraponiéndolo a Alejandro Mago, quien por el contario se había comprometido a restaurar la torre de Babilonia. Esta actitud resulta comprensible, pues el monarca aqueménida había infringido a los griegos derrotas muy severas y destruido la acrópolis de Atenas. Sin embargo, las excavaciones no demuestran que se produjesen cambios drásticos en la estructura de la ciudad durante la dominación aqueménida. De hecho, Ctesias, que junto con Heródoto, es uno de los autores más cercanos a la historia de Persia nada dice de la destrucción de los templos de Babilonia por el rey Jerjes. Este relato de la destrucción se ha conservado en dos autores tardíos como son Focio (s. IX d.C.) y Eliano (ss. II-III d.C.) $)^{29}$.

El geógrafo Estrabón relata que cuando Alejandro Magno conquistó Babilonia en el año 331 a.C. tenía entre sus proyectos la reconstrucción del zigurat, que en aquella época debía estar dañado. El autor calcula que sólo la evacuación de los escombros representaría trabajo para 10.000 hombres durante dos meses ${ }^{30}$. No obstante, de regreso a Babilonia en 323 a.C., Alejandro Magno no tuvo la oportunidad de cumplir sus planes, puesto que la muerte le sorprendió en esta ciudad, apenas cumplidos los 33 años $^{31}$. Además de Estrabón y Arriano, se conservan dos tablillas cuneiformes procedentes de Babilonia, que mencionan trabajos de restauración del templo y la retirada de escombros de la torre ${ }^{32}$. El zigurat debía estar deteriorado, que no destruido, tras la ocupación aqueménida por falta de mantenimiento. Alejandro Magno como "rey de Asia" asumió su papel de "rey constructor" al modo de los grandes soberanos babilónicos, con el objetivo de ganarse el apoyo de los sacerdotes y, por extensión, de los dioses.

Hacia 300 a.C. los sucesores del conquistador macedonio abandonaron la ciudad a favor de una capital nueva en el Tigris, Seleucia. Los motivos de este traslado no fueron tanto políticos como económicos, pues el río Tigris se había convertido en una vía de acceso mucho más cómoda al Golfo Árabo-Pérsico. Esto no significó, sin embargo, el fin de su importancia religiosa y cultural. La dinastía seléucida sufragó el mantenimiento de los templos de la ciudad,

\footnotetext{
${ }^{23}$ George 2005/2006, p. 79; George 2011.

${ }^{24}$ George 2005/2006, p. 88.

${ }^{25}$ Schmid 1995, p. 75.

${ }^{26}$ Geografía XVI, 1, 5; Anábasis VI, 17.

${ }^{27}$ George 2010.

${ }^{28}$ Kurth y Sherwin-White 1987, p.69-78; Kurth 2010 y 2014.

${ }^{29}$ Kurth 2014, p. 167.

${ }^{30}$ Geografía XVI, 5.

${ }^{31}$ Kuhrt 1990, p. 127 considera que la reconstrucción de los santuarios de Babilonia por Alejandro respondía más a una cuestión relacionada con el respeto a la tradición babilónica que a la necesidad de reparar los templos debido a su mal estado de conservación.

${ }^{32}$ Crüsemann 2011, p. 104.
} 
en particular del Esagil, y participó en los festivales religiosos en honor del dios Bêl-Marduk ${ }^{33}$. Las referencias al zigurat Etemenanki en copias de textos babilónicos tardíos ya no hablan de su existencia como un lugar sagrado en el período helenístico. En el siglo III a.C. la superestructura del zigurat había sido desplazada a otra zona de la ciudad ${ }^{34}$. Homera, el gran tell de ruinas situado en el ángulo noreste de la ciudad interna, contenía los escombros del Etemenanki, a donde habían sido desplazados con la ayuda de elefantes en tiempos de Antíoco I (280-261 a.C. $)^{35}$.

A luz de la documentación disponible, y a modo de síntesis, estas son las grandes fases históricas de construcción, destrucción y restauración documentadas del zigurat de Babilonia:

\begin{tabular}{|c|c|c|}
\hline $\begin{array}{l}\text { Dinástico Antiguo III / } \\
\text { Akkad }\end{array}$ & --- & Ciudad pre-zigurat \\
\hline Ur III & --- & $\begin{array}{l}\text { Orígenes y fundación de la } \\
\text { ciudad de Babilonia y del } \\
\text { zigurat (hipótesis). }\end{array}$ \\
\hline Paleobabilónico & --- & $\begin{array}{l}\text { Fundación de la ciudad } \\
\text { de Babilonia y del zigurat } \\
\text { (según otros autores). }\end{array}$ \\
\hline $\begin{array}{l}\text { Mediobabilónico / } \\
\text { Neobabilónico Inicial }\end{array}$ & --- & $\begin{array}{l}\text { Hay referencias textuales } \\
\text { sobre la existencia del } \\
\text { zigurat. }\end{array}$ \\
\hline & Senaquerib (689 a.C.) & Destrucción \\
\hline Dominación Neoasiria & $\begin{array}{l}\text { Asarhadón (680-669 a.C.) } \\
\text { Asurbanipal (668-630 a.C.) } \\
\end{array}$ & Reconstrucción \\
\hline Neobabilónico Clásico & $\begin{array}{l}\text { Nabopolasar (626-605 a.C.) } \\
\text { Nabucodonosor II (604-562 a.C.) } \\
\text { Nabónido (556-539 a.C.) }\end{array}$ & $\begin{array}{l}\text { Reconstrucción y } \\
\text { finalización del zigurat } \\
\text { Reconstrucción del muro } \\
\text { del recinto. }\end{array}$ \\
\hline Persa aqueménida & Jerjes (484 a.C.)? & $\begin{array}{l}\text { Destrucción, según } \\
\text { algunos autores clásicos. }\end{array}$ \\
\hline Macedonio & Alejandro Magno (331-323 a.C.) & $\begin{array}{l}\text { Inicio de las obras de } \\
\text { reconstrucción. }\end{array}$ \\
\hline Helenístico & $\begin{array}{l}\text { Seleuco I (305-281 a.C.) } \\
\text { Antíoco I (280-261 a.C.) }\end{array}$ & $\begin{array}{l}\text { Decadencia de la ciudad } \\
\text { en favor de Seleucia del } \\
\text { Tigris. } \\
\text { Desplazamiento de las } \\
\text { ruinas del zigurat a la } \\
\text { colina llamada Homera. }\end{array}$ \\
\hline
\end{tabular}

\footnotetext{
${ }^{33}$ Boiy 2004, p. 264ss; George 2005/2006, p. 91.

${ }^{34}$ George 2005/2006, p. 89.

${ }^{35}$ Bergamini 2013, p. 57-61.
} 
El proceso de destrucción del zigurat debió de ser rápido, ya que a partir de la Edad Media los viajeros que visitaban la región fueron incapaces de localizar correctamente el zigurat de Babilonia, la bíblica torre de Babel. Entre los viajeros europeos de los siglos XIIXIX reinará una gran confusión con respecto a la ubicación de la torre, ya que en su época sólo debía de ser una pequeña colina apenas visible en el relieve ${ }^{36}$. Sabemos que el expolio de los restos de la torre, en particular, de los adobes cocidos para la construcción de las casas, los pueblos e incluso de una presa en el río Éufrates, continuó especialmente durante el siglo XIX. El célebre monumento se había convertido en una magnífica cantera de materiales de construcción. El resultado fue la desintegración casi completa del zigurat babilónico.

El expolio del monumento, que llegó hasta la base de la cimentación de la primera terraza, provocó la inundación paulatina con aguas procedentes del nivel freático de la zanja perimetral externa nacida de la extracción de materiales del manto de revestimiento de adobes cocidos. En este lamentable estado encontró Robert Koldewey el edificio que, gracias a la sequía excepcional de 1913, pudo excavar y dibujar en un plano.

En abril de 2003, con la ocupación de Iraq durante la llamada Segunda Guerra del Golfo, las ruinas de Babilonia se transformaron en un campamento militar de 150 hectáreas, que llegó a albergar hasta dos mil soldados de la coalición internacional. Los daños que ha sufrido Babilonia han sido irreparables. En la zona del zigurat, por ejemplo, se excavaron varias trincheras antitanques, algunas de $170 \mathrm{~m}$ de longitud ${ }^{37}$.

Lo que en la actualidad se puede observar en el lugar donde se levantó un día el zigurat de Babilonia no hace honor a la grandeza que en la Antigüedad hizo célebre a este monumento. Hoy tan sólo se conserva su emplazamiento impreso en el suelo, una fosa rellena de agua y cañas y, en el centro, los restos de adobe del núcleo del edificio (FIGURAS 1 Y 2).

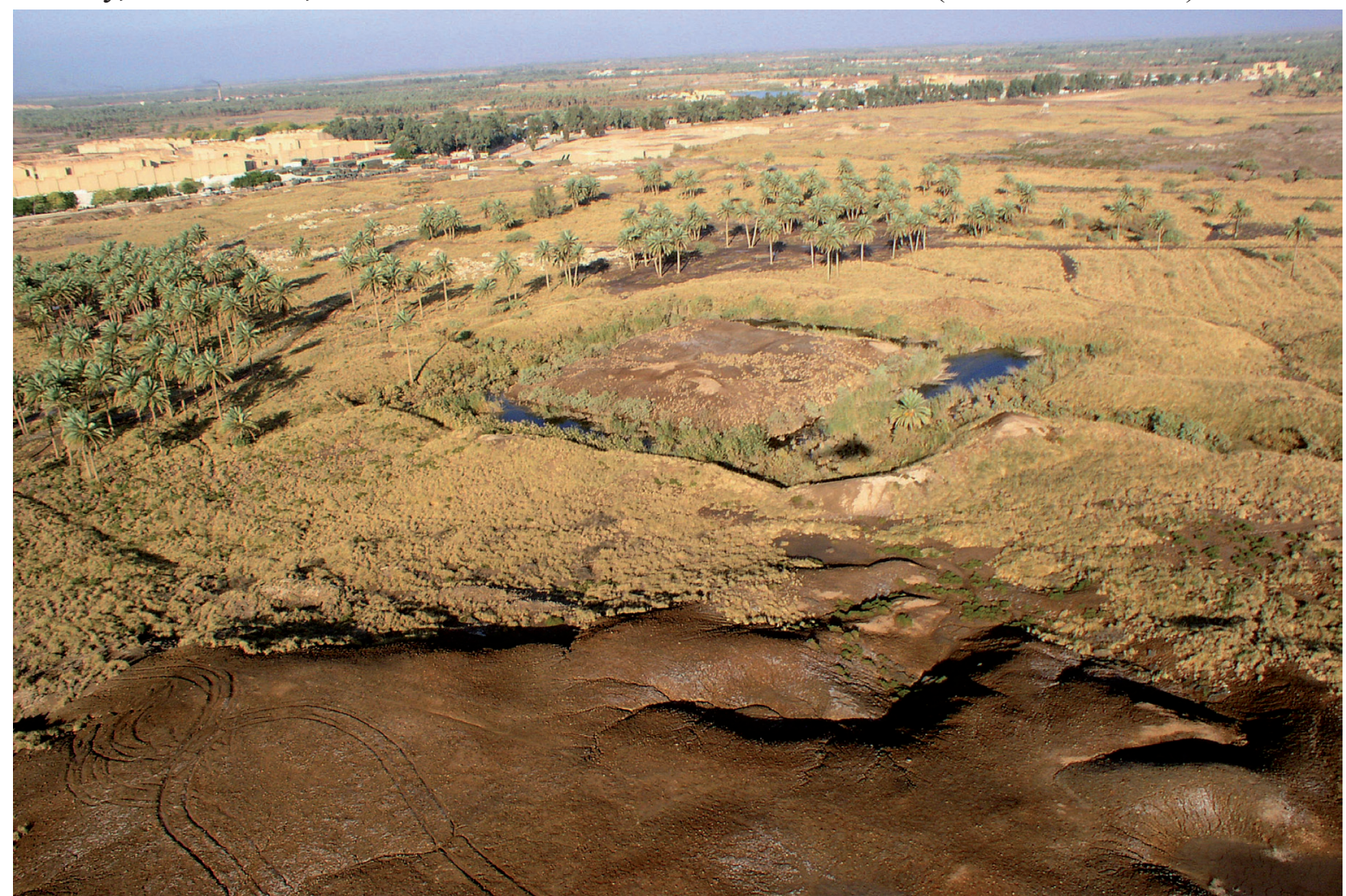

Fig.1. Estado actual del zigurat de Babilonia (foto: R. Kolinski).

\footnotetext{
${ }^{36}$ Montero Fenollós 2011.

${ }^{37}$ Curtis 2008.
} 


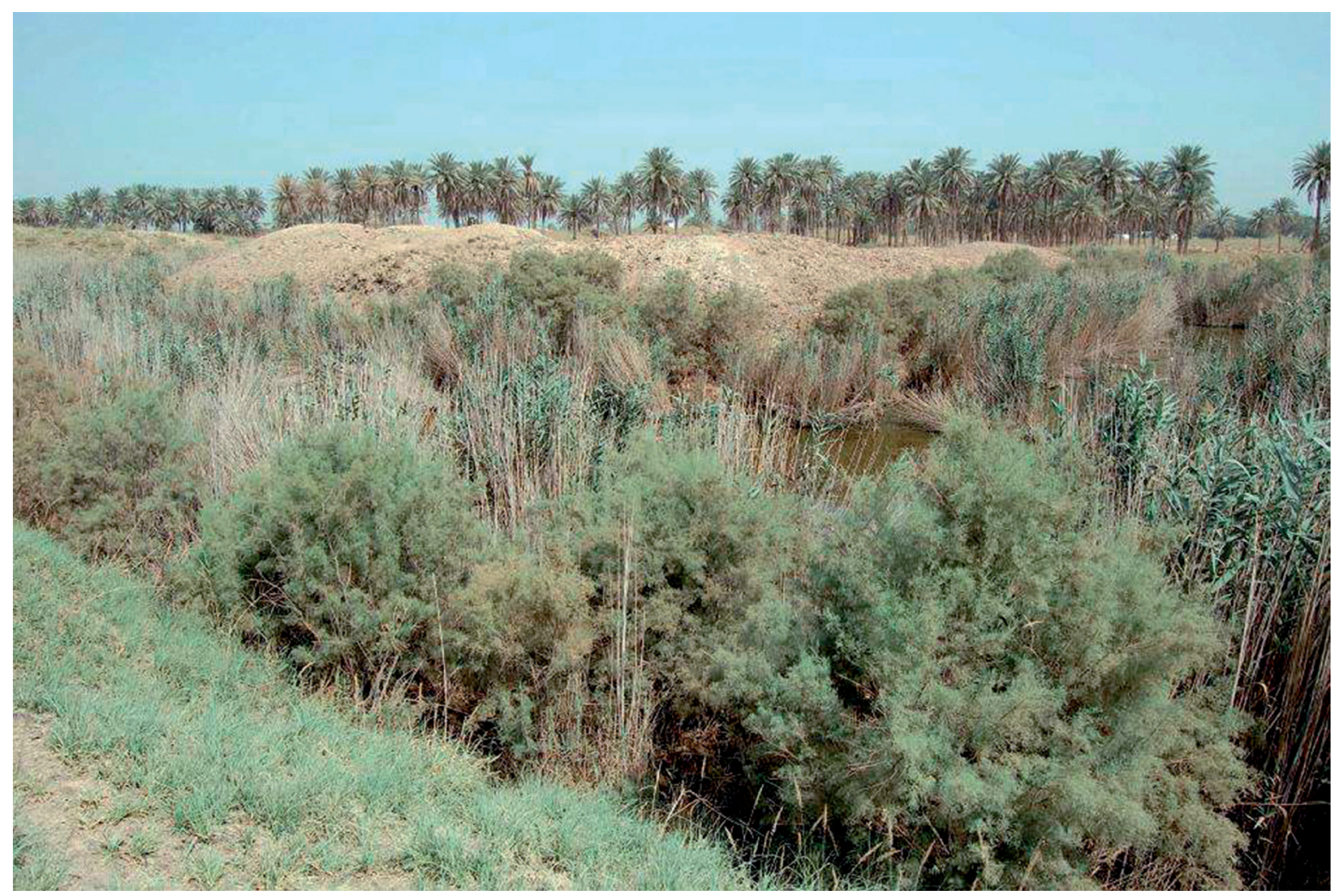

Fig.2. Estado actual del núcleo del zigurat de Babilonia (foto: J. Rusell).

\section{REFERENCIAS}

ANDRÉ-SALVINI, B.

2001 Babylone, Paris.

BEAULIEU, P.A.

2003 "Nabopolassar and the antiquity of Babylon", in I. Eph'al et al. (eds.), EretzIsrael, Hayim and Miriam Tadmor volume, Jerusalem, pp. 1-9.

BERGAMINI, G.

2013 "Fondations dans l'eau. Réflexions à la suite des recherches et des fouilles archéologiques italiennes à Babylone", in B. André-Salvini (dir.), La tour de Babylone. Études et recherches sur les monuments de Babylone, Roma, pp. 43-63.

BOIY, T.

2004 Late Achaemenid and Hellenistic Babylon, Leuven.

BOTTÉRO, J. y KRAMER, S.N.

1993 Lorsque les dieux faisaient l'homme. Mythologie mésopotamienne, Paris.

COLE, S.-W. Y MACHINIST, P.

1998 Letters from Priests to the kings Esarhaddon and Assurbanipal, SAA 13, Helsinki. 


\section{CRÜSEMANN, N.}

2010 "Alejandro en Babilonia y la herencia del Antiguo Oriente", in S. Hansen et al. (eds.), Alejandro Magno. Encuentro con Oriente, Madrid, pp. 99-107.

CURTIS, J.E.

2008 "Le Site de Babylon Today", in I.-L. Finkel, M.-J. Seymour (eds.), Babylon. Myth and Reality, London, pp. 213-220.

FINET, A.

2004 Le code de Hammurabi, Paris.

FRAME, G.

1995 Rulers of Babylonia from the Second Dynasty of Isin to the end of Assyrian Domination, RIMB 2, Toronto.

GEORGE, A.R.

1992: Babylonian Topographical Texts, Leuven.

1993 House Most High. The Temples of Ancient Mesopotamia, Winona Lake.

2005/2006 "The Tower of Babel, archaeology, history and cuneiform texts", Archiv für Orientforschung, 51, pp. 75-95.

2010 "Xerxes and the Tower of Babel", in J. Curtis, J. Simpson (eds.), The World of Achaemenid Persia, London, pp. 472-480.

2011 Cuneiform Royal Inscriptions and Related Texts in the SchØyen Collection, Bethesda.

\section{GIBSON, M.}

1972 The City and Area of Kish, Miami.

KUHRT, A.

1990 "Alexander and Babylon", Achaemenid History, 5, pp. 121-130.

2010 "Xerxes and the Babylonian Temples: A Restatement of the Case", in J. Curtis y J. Simpson (eds.), The World of Achaemenid Persia, London, pp. 491-494.

2014 "Reassessing the reign of Xerxes in the light of new evidence", in M. Kozuh et al. (eds.), Extraction and control. Studies in honor of Matthew W. Stolper, Chicago, pp. 163-169.

KUHRT, A. y SHERWIN-WHITE, S.

1987 “Xerxes' Destruction of Babylonian Temples”, Achaemenid History 2, pp. 69-78.

LAMBERT, W. G.

2011 "Babylon: origins", in E. Cancik-Kirschbaum, M. Van Ess y J. Marzahn (eds.), Babylon. Wissenskultur in Orient und Okzident, Berlin, pp. 71-76.

MARGUERON, J.C.

2001 "Aux origines du plan de Babylone", in C. Breniquet, Ch. Kepinski (ed.), Études mésopotamiennes. Recueil de textes offert à Jean-Louis Huot, Paris, pp. 323-345. 
MONTERO FENOLLÓS, J.L.

2011 "The Tower of Babel before Archaeology. The Ziggurat of Babylon according to European Travelers (XII-XVII centuries)”, Res Antiquitatis, 2, pp. 31-49.

SCHMID, H.

1995 Der Tempelturm Etemenanki in Babylon, Mainz am Rhein.

VON SODEN, W.

1971 "Etemenanki vor Asarhaddon nach der Erzählung vom Turmbau zu Babel dem Erra-mythos", Ugarit Forchungen, 3, pp. 253-263. 